\title{
HOMBRE Y NATURALEZA EN EL HEXAEMERON DE GROSSETESTE
}

Celina A. Lértora Mendoza*

SINTESIS - El articulo analiza el tema de la relación del hombre con la naturaleza en el Hexaemeron de Grossetesste, tratado de teologia bíblica en el que, a partir de la exégesis del relato de la creación, plantea los principales temas de la fe cristiana procurando concordarlos con los conocimientos cientificos de su tiempo. Los ejes fundamentales son: 1. Todas las cosas fueron creadas por Dios; 2. Las cosas fueron creados ordenadamente según la relativa perfección de sus naturalezas; 3 . La creación es un sistema "cerrado" y todo lo que en ella se contiene puede ser explicado a la vez por la fe y la razon; 4. El universo (creado) es finito temporal, espacial y cualitativamente. Con estos postulados se fundamenta la dignidad del hombre contenida en su carácter de "imagen de Dios", que se trasunta en: aser imagen de Dios Uno y Trino; b. ser un "microcosmos" o compendio de todo lo creado; c. ser necesariamente una sola especie y d. ser el señomatural de todas las cosas.

PALABRAS-CLAVE - Roberto Grosseteste. Hexaemeron. Creación. Hombre y naturaleza.
ABSTRACT - The article analyses the subject of the relationship of man and nature in the Hexaemeron by Grosseteste, a treatise on Biblical Theology in which, starting at he exegesis of the narrative of creation, states the leading matters of Christian faith trying to put them in accordance with the scientific knowledge of the time. The fundamental axes are: 1. All things were created by God. 2. Things were created orderly following the relative perfection of their own natures. 3 . Creation is a "locked" system and everything inside it can be explained both by faith and reason. 4. The Universe (which is created) is finite, temporal in qualitative and espacial senses. On these postulates is founded the dignity of man involved in his character of "image of God" apparent in: a. Being image of God one and triune; b. Being a "microcosm" or epitome of all of the created; c. Being necessarily one only kind and d. Being the natural master of all things.

KEY WORDS - Robert Grosseteste. Hexaemeron. Creation. Man and nature.

El hombre y la naturaleza son dos temas que el Medioevo ha considerado asiduamente, sobre todo en función de la exégesis del relato de los "seis días" (Gen. I, 1-26). Afirmaciones decisivas para la visión cristiana (o judeo-cristiana) se condensan en esos breves párrafos: la idea de creación en virtud de una voluntad divina omnipotente y libre, el plan o estructura jerarquizada de la naturaleza cuya cúspide es el hombre, la impresión de "vestigios" de Dios en las cosas y de una "imagen" de Dios en el hombre, la potestad sobre todo lo creado otorgada por el creador, la caida de Adán y las consecuencias del pecado en lo atinente a la relación con la naturaleza.

* Instituto Teológico Franciscano. CONICET: Consejo Superior de Investigacions Científicas y Tecnologicas - Buenos Aires. 
Una larga serie de comentarios de los Santos Padres jalonan la historia de este texto, que gozó de todos los tipos de exégesis habituales en el medioevo; literal, alegórica, anagógica y moral. Quizá el ejemplo culminante de esta plurivocidad exegética lo constituya el Hexaemeron de San Basilio, lo que también explica que fuera modelo y fuente de otras lecturas determinadas luego por otros intereses teológicos o filosóficos.

Sin embargo, la literatura hexaemeral llega a su ocaso conjuntamente con el afianzamiento de un nuevo paradigma de comprensión del cosmos: el aristotélico. Solidaria en buena medida con la visión platónica del cosmos y su ejemplarismo, la tradición hexaemeral había logrado todos sus frutos llegando al limite de las posibilidades de ampliación hermenéutica. Se imponía más bien una relectura y redistribución de los temas, más acorde con el tipo de trabajo intelectual del s. XIII. Esta tarea fue cumplida por Roberto Grosseteste con su versión del Hexaemeron, ${ }^{1}$ que intenta recoger ordenada y sistemáticamente toda la riqueza patristica y monástica sobre el tema, pero respetando al mismo tiempo, y en la medida de lo posible, los nuevos cánones de cientificidad discursiva.

En su conjunto, el Hexaemeron constituye una especie de "Suma" de la teología bíblica tal como se la entendia en esta primera mitad del siglo, cuando todavía se siente con fuerza la influencia de la tradición victorina. Las cuestiones relativas al objeto y método de la teología se exponen en el "Proemium" y luego, siguiendo el hilo del relato genésico, van apareciendo, en forma directa o como anticipaciones, todas las verdades fundamentales de la fe cristiana. Pero al mismo tiempo se muestra la relación de acuerdo y complementariedad con las concepciones científicas aceptadas por Grosseteste, provenientes de los sabios paganos, fundamentalmente Aristóteles. Esta obra fue escrita o al menos esbozada en sus lineamientos c. 1235, es decir, en la época de la plenitud de los trabajos científicos del Lincolniense, siendo contemporáneo al Comentario a la Physica y a otros opúsculos de madurez. ${ }^{2}$ Es posible que su redacción le llevara muchos años, hasta cerca de su muerte (1253) por lo cual habría aprovechado la experiencia propia y de su grupo en relación con las traducciones y comentarios a algunas obras con temas conexos, como la Ethica aristotélica y el corpus dionisiano. ${ }^{3}$

\footnotetext{
Se cita por la edición de Richard C. Dales Servus Gieben, Oxford, University Press, 1982.

Cf. "Introduction", ob. cit, p. xi ss. y "The Proemium to Robert Grosseteste' Hexaemeron", Speculum 43, 1968, n. 3: 451-461 donde se relaciona la época de composición con su aprendizaje del griego. Sobre esto v. tambien J. T. Muckle, "Robert Grosseteste's use of greek source in this HexaemeIon", Medievalia et Humanistica 3, 1945: 33-48, quien detaca el evidente interés por los Padres griegos, aunque vertidos en terminología agustiniana.

J Sobre la importancia de esta obra en relación a otras de madurez y a su influencia, v. J. T. Muckle, "The Hexaemeron of Robert Grosseteste", Mediaeval Studies 6, 1944: 151-174, quien señala la doctrina trinitaria en relación con la idea lumínica como uno de los aspectos más importantes, y R. C. Dales, "The influence of Robert Grosseteste's Hexaemeron on the Sentences Commentaries of Richard Fishacre OP and Richard Rufus of Cornwal OFM". Viator 2, 1971: 271-300. Ambos autores mencionados usaron esta obra y tomaron de ella varias doctrinas. Particularmente, en cuanto ahora nos ocupa, señalemos que tomaron sus ideas exegéticas sobre la creación del hombre a imagen de Dios, la no eternidad del mundo (el "en el principio" del Moisés), la imagen trinitaria en el hombre y muchas aplicaciones de la teoria de la luz.
} 
En la Parte octava, luego de haber explicado ampliamente los actos divinos de creación de la naturaleza, se aborda la creación del hombre y su suprema dignidad entre las demás cosas naturales. En la parte novena se analiza la relación del hombre con la naturaleza derivada del habitat que Dios le otorgó, así como el dominio que le confirió sobre todas las cosas. Es en este punto en que me centraré especialmente ahora.

Para entender el sentido de estos textos debemos tener en cuenta que si bien contienen argumentaciones de tipo filosófico, son en realidad teológicos, lo que significa que dichas argumentaciones parten de asunciones que no se prueban ni discuten, sino que se aceptan como verdades de fe, aunque su razonabilidad o su congruencia con la razón y la experiencia se pongan siempre de manifiesto. Es a partir de estas afirmaciones o asunciones que se desarrolla la visión del lugar del hombre en el cosmos y el sentido de la totalidad. Por eso organizaré mi exposición tomando como eje estas afirmaciones básicas.

Por lo tanto, la "filosofia" de Grosseteste sobre las relaciones entre el hombre y la naturaleza resultan de una reconstrucción racional. La justificación de ella misma requiere todavía algunas palabras.

Como en toda reconstrucción, en este caso hay que señalar en primer lugar cuál es el criterio según el cual se extraerán "piezas teónicas" de un contexto para colocarlas en otro, y evitar la objeción esperada de que ese "mosaico" final corre el riesgo de ser una invención del intérprete. En mi concepto, para superar este obstáculo es necesario que se cumplan dos condiciones: $1^{2}$ que los elementos teóricos a componer se encuentran todos explícita o implícita, pero claramente, en la obra de Grosseteste; $2^{2}$ que la re-exposición no desvirtúe el sentido original de los textos usados.

La primera condición se cumple en la medida en que hay una base textual amplia y sólida, dada por el Hexaemeron mismo, que es muy explicito y detallado en casi todos sus aspectos. La segunda es quizá un poco más problemátíca. En efecto, Grosseteste escribió aquí como teólogo, y en cuanto pensador, su posición filosófica dependia en gran medida de sus propias creencias religiosas. Aun en los casos en que no se expresaba como teólogo (por ejemplo, como comentador de las obras físicas de Aristóteles) no podía evitar su adhesión impertérrita a las ideas cristianas. No hay en él, como por lo demás en ningún - o casi ningún medieval una postura "filosóficamente pura" (supuesto que eso sea posible, aun en otras épocas), es decir, no condicionada en alguna medida por cosmovisiones o ideologias asumidas acriticamente. Una respuesta fácil y ad hominem señalaría que cualquier filósofo está en igual situación (ya que todos tienen sus creencias, afectos, adhesiones, etc. que de un modo u otro influyen más o menos en su obra o en su peculiar visión de los problemas filosóficos y sus posibles soluciones) y que por tanto ninguna exposición pretendidamente "neutral" u "objetiva" sería válida a menos que fuera estrictamente "especular" y por tanto superflua. Y la

El tema de la dignidad humana es encarado por Grosseteste retomando una tradición que se remonta hasta Gregorio de Nisa, y que considera que la excelencia del hombre es tan manifiesta en la belleza y función del cuerpo como en la racionalidad (cf. R. C. Dales, "A medieval view of human dignity", Joumal of history of ideas 38,1977 , n. 4: 557-572). 
razón es que cualquier otro pensador pondría "lo suyo" en esta reconstrucción, con lo cual tergiversaría más o menos gravemente el original. Asumo que este es el riesgo de cualquier hermenéutica y que es inevitable. Sin embargo, considero que hay algunos parámetros que podríamos estimar "objetivos" en el sentido de "verificables intersubjetivamente" que hacen verosímiles o aceptables algunas interpretaciones. Así, si bien Grosseteste no escribió explícitamente una filosofía del hombre y la naturaleza, ha hablado del tema filosóficamente, aunque en un contexto teológico. Y en la medida en que él mismo aceptaba no sólo la filosofia como una rama válida del saber, sino aún más, que la filosofía tiene su propia esfera cognitiva, resulta aceptable desglosar estos elementos filosóficos de su contexto global y presentarlo como una visión filosófica - naturalmente cristiana de un problema que afecta por igual, aunque de diverso modo, a filósofos y creyentes. Por lo tanto, la reconstrucción debe hacerse reconociendo en primer lugar el contexto afirmativo (dogmático) de donde se extraen las tesis que funcionan como axiomas o premisas de las argumentaciones y explicaciones ulteriores.

\section{Las afirmaciones fundamentales y la teoria filosofica derivada}

\section{Todas las cosas fueron creadas por Dios}

Esta es la afirmación central e inicial de toda consideración del hombre y la naturaleza: su coincidencia ontológica en cuanto creaturas. Este carácter, que se analiza ampliamente en la Parte primera, ${ }^{5}$ implica las siguientes tesis: 1 . La creación es un acto absolutamente diferente de los otros y sólo producto de la divinidad; 2. Todas las cosas, sin excepción, salvo Dios, fueron creadas; 3 . Crear se distingue de "hacer" o cualquier otro acto semejante en que es la producción de algo a partir de nada; 4. Sólo Dios es eterno e incausado, todo lo demás es finito y causado; 5. Esta creación (el conjunto de las cosas creadas) tiene una duración finita a parte ante, incluso las sustancias espirituales.

5 Adam Marsh, discípulo y sucesor de Grosseteste en Oxford, hizo un sumario o resumen brevísimo de los capítulos de toda la obra, que nos sirve para detectar cuál era, según estos destinatarios iniciales, el punto teórico central en discusión (ed. en Hexaem. cit. p. 341-350). De los 24 capítulos de la Parte primera, los siguientes tienen relación directa o indirecta con las discusiones filosóficas implicadas en el relato biblico: 7. "Primera exposición literal, es decir, qué pretende en primer lugar la letra de la obra de los seis días"; 8. "Refutación de la posición de los filósofos de que el mundo no tuvo inicio temporal, por el significado de la palabra principio, cuando se dice en el principio creó Dios el cielo y la tierra"; 9. "Refutación de los filósofos que afirman la existencia de muchos principios coeternos, por la significación de la palabra principio"; 10. "Distinción de la palabra principio, donde se evidencia a cualquier entendimiento que esta palabra principio va unido a él mismo cuando se dice en el principio, etc."; "Qué debe entenderse por la significación y consignificación de lo que dice creó o hizo"; 15. "Se demuestra que Dios creó la materia de la nada y que no produjo el mundo de una materia ingénita"; 16. "Se investiga si el primer cielo que circunda todos los cuerpos del mundo, es el mismo firmamento que se menciona en el segundo día o es otro"; 17. "Se exponen cinco razones acerca de que: si el primer cielo es distinto del firmamento creado en el segundo día, es inmóvil". Como vemos, en la versión sintética de Marsh y los demás discipulos oxonienses de Grosseteste interpretaban estos textos como un diálogo controversial con los filósofos paganos y como intento de afirmar teóricamente la posición cristiana. 
Este carácter de todas las cosas las emparenta entre sí, en cuanto creaturas. Frente a la herejía maniquea (explicada y refutada en los capítulos 23 y 24 de la Parte primera), cuya versión albigense estaba provocando en la Europa contemporánea a Grosseteste una sanguinaria guerra religioso-política, se insiste en la bondad ontológica universal: todas las cosas son buenas por el solo hecho de existir." El desarrollo teórico del bien trascendental se relaciona tanto con la ontología aristotélica como con el texto bíblico ("y vio Dios que era bueno", se repite al cabo de cada acto creacional).

El universo, dentro de su limitación como creatura, es perfecto. Si fuera sobreabundante, habría algo fuera del universo, lo que no es posible. Si se contrajera en algo menos que si, no habría universo. Por tanto, concluye Grosseteste, el universo o mundo no puede ser sobreabundante ni disminuido, sino igual a sí mismo.' La relación de las cosas creadas entre sí, que Grosseteste ejemplifica matemáticamente con la progresión aritmética que da por resultado el número seis $(6=1+2+3)$ se vincula con la idea de la expansión de la forma primordial que es luz: si se considera la expansión de la luz creada el primer día, se produce una figura triangular que va desde el sol (tercera esfera) a las estrellas fijas (última esfera) y al centro de la tierra. En esa línea que une el centro de la tierra con la esfera estelar hay secciones que responden a los distintos seres vivientes que pueblan el mundo sublunar: los peces, los reptiles, las bestias y las aves. ${ }^{\circ}$ De este modo el relato bíblico se hace concordar con la biología griega, que establecia la existencia de regiones naturales para las especies conforme a su diverso grado de complejidad.

\section{Las cosas fueron creadas ordenadamente según la relativa perfección de sus naturalezas}

El sentido de esta afirmación es que cada cosa es perfecta en su especie y el conjunto ordenado (armónico, estructurado) de todas ellas (el universo) es también perfecto, y por eso es bueno. Y lo fue desde el primer instante, aun cuando todavía no estaban creadas todas las cosas. En otros términos: no hay una "evolución" hacia la bondad desde un estadio menos bueno o no bueno (en

6 El interés de refutar al maniqueismo albigense y no sólo combatirlo con la espada llevó seguramente a remozar las antiguas ideas boecianas e incluso a centrar en el concepto de "bien" la exposición de los temas fundamentales de la metafísica, como por ejemplo la Summa de bono de Felipe el Canciller, cuyas relaciones con Grosseteste son bastante significativas. Las relaciones entre la obra de Felipe y el De anima atribuido a Grosseteste han sido estudiadas por D.A. Callus, "Philip the Cancelor and the De anima adceibed to Robert Grosseteste", Medieval and Renaissance Studies 1, 1941.1943: 104-127. Para este investigador, el autor de la compilación atribuida a Grosseteste seria Felipe. Por su parte L. Keeler sostiene que el De anima es una versión (a veces resumida y otras ampliada) de la obra de Felipe, que habría sido originada en una reportatio de las lecciones de Felipe en Paris (cf. "The dependence of R. Grosseteste's De anima on the Summa of Philip the Chanchellor", New Scholasticism 11, n. 137: 197-219). Sin entrar en estas discusiones, y sea que aceptemos o no la autoria del Lincolniense (que hoy prácticamente es negada) está claro que en el círculo de intereses intelectuales próximos a Grosseteste pesó la influencia del Felipe.

7 "I...] nec superfluum nec diminutum esse potest, se sibi ipsi equale"... Hexaem. IX, 1, 1 (ed. cit. p. 263).

8 Hexaem. IX, 1, 3 y 4 (ed. cit. p. 263 ss). 
sentido ontológico). Si se lee con cuidado los párrafos 1 y 2 del capitulo VII de la Parte primera (ver Apéndice), se aprecia el interés por explicar la historia del mundo a la vez desde la perspectiva biblica y cientifica.

Esta perfección del universo en todo y en sus partes es una condición de la aparición del hombre, porque no sería congruente, dice Grosseteste, que apareciera la creatura más perfecta (tal como es el hombre) si el mundo no hubiese estado terminado en forma adecuada para él.' Esta percepción de una escala genética que va de lo más simple a lo más complejo, si bien el Lincolniense la justifica fácilmente con el Génesis, responde también a un interés filosófico por explicar las relaciones entitativas y causales en el universo. En efecto, la línea de causalidad, conforme al criterio aristotélico, va de lo más perfecto a lo más imperfecto y no a la inversa, es decir, no es evolucionista, aunque pudiera recibir una interpretación emergetista.

\section{La creación es un sistema "cerrado" y todo lo que en ella se contiene puede ser explicado a la vez por la fe y la razón}

Grosseteste, como todos los escolásticos ortodoxos del s. XIII, es "concordantista". Para él no sólo no hay contradicción entre el "libro revelado" y el "libro natural" sino que entre ellos hay un perfecto acuerdo y complementación. Esta asunción le permite utilizar los datos aportados por sendas esferas en sentidos cruzados. Cuando justifica la extensión y orden de los textos bíblicos (I, $4,1)$ es muy claro al respecto:

"Esta escritura [la Biblia] contiene en sí todo lo que contiene la naturaleza, porque después de la creación del mundo no hay añadido de nuevas especies o naturalezas. Contiene también todo lo que está sobre la naturaleza, que es nuestra reparación y futura glorificación. Contiene también toda la moralidad y toda la ciencia racional. Pues el mismo mundo arquetípico es razón, arte, regla y ciencia racional de todas las cosas. En el mismo está toda causa de subsistencia, razón de inteligibilidad y orden de vida." ${ }^{\text {th }}$

Además de la afirmación fijista (que luego se atenúa siguiendo a S. Agustín), resalta aquí la autosuficiencia bíblica: todo lo que se puede aprender en la ciencia secular está contenido en estos textos, en forma más abundante, sencilla y humilde. Pero esta constatación implica a la vez el reconocimiento de que al menos parte de lo que se dice en la Escritura se puede saber investigando con la razón natural, y que este orden de verdades no es paralelo sino unificado. Por eso es legítimo discutir con los paganos desde la perspectiva cristiana, pues aunque hablan desde puntos de partida diferentes (la pura razón y la fe), se refieren a lo mismo en la realidad y el sistema de veritativo es unitario. Para Grosseteste, en quien se ve claramente la transición entre la filosofía del s. XII y la del XIII, el naturalismo científico y el simbolismo cristiano no son inconciliables." Por eso la

Hexaern. IX, 1, 5 (ed. cit. p. 265).

Ed. cit., p. 54.

Cf. J. Mc Evoy, "Man and cosmos in the philosophy of Robert Grosseteste", Revue philosophique de Louvain 72, 1974: 826 ss. (resumen) y en volumen, Louvain, 1974. 
sabiduría humana puede subordinarse sin temor a la revelación, lo que le permite usar sin reservas el método cientifico aristotélico corrigiéndolo sólo por control negativo con la Biblia.

Esta visión es la que le permite analizar el complejo tema de las relaciones entre el hombre y el universo, conjugando dos viejos temas de la tradición patrística y monástica: el hombre imagen de Dios y el hombre microcosmos. De ese modo, postulando que el orden humano imita el orden perfecto de las cosas, puede extraer consecuencias de índole descriptiva y a la vez práctico morales.

La teoria general que relaciona las cosas con el hombre es la del "vestigio", que se vincula al ejemplarismo platónico agustiniano. Para la tradición que Grosseteste asume, la dependencia de todas las cosas con respecto a su causa hace que ellas presenten "trazas" o vestigios suyos. ${ }^{12}$ Pero el ejemplarismo de Grosseteste no se reduce a la semejanza de la creatura con las ideas eternas divinas, que es sólo un aspecto de la cuestión, sino que, penetrando en la naturaleza de las cosas considera que hallará cientificamente esas semejanzas." Por eso puede conjugar la ciencia con la fe.

\section{El universo (creado) es finito temporal, espacial y cualitativamente}

La finitud del mundo está dada por el cierre creacional en el sexto día. Las sucesivas transformaciones del mundo no son objeción a este principio porque los procesos de generación y comupción de los individuos no alteran las especies. La finitud del mundo es una finitud específica, no individual. La tarea divina de incrementar, mover, gobernar, reparar y atraer, que Grosseteste reconoce conforme al texto paulino" no implican novedad específica y por la misma razón tampoco la creación posterior de almas humanas altera el definitivo reposo de Dios creador. ${ }^{15}$

${ }^{12}$ La doctrina de la creación de la Escuela de Chartres, que asume y resume el amplio movimiento exegético anterior, puede ser considerada el antecedente inmediato de algunas de las ideas que vamos viendo. Un estudio de conjunto sobre el tema en J. N. Parent, La doctrine de la création dans l'école de Chartres, Paris, 1938.

13 Cf. S. Gieben, "Traces of God in nature according to Robert Grossetesten, Franciscan Studies 24, 1964: 144-158.

1 Cor. 3,7 y Ac. $17,28$.

15 Hexaem. IX, 3, 1 (ed. cit., p. 269) Grosseteste rechaza la interpretación de quienes, queriendo preservar el absoluto reposo divino deducian que todos los individuos fueron creados al principio y que las almas son educidas de una materia preexistente. El Lincolniense no estima necesario referir la solución a cualquier tipo de "razones seminales" sino que basta con el fijismo específico para garantizar la unidad creacional del universo: "I...] así como el primer hombre tuvo su alma de la nada, también los demás. No pudo ser de una materia preexistente porque siendo sustancia, no puede producirse del accidente; y siendo mutable no puede producirse de Dios como de una materia; como es espiritual incorpórea no puede producirse de una materia corpórea, y como es racional no puede provenir de un irracional ni de un racional, porque toda alma racional es alma o ángel, ní puede ser una para todos los hombres porque un alma es distinta a otra (una es justa, otra injusta). Por tanto cada hombre recibe su alma por creación sin ninguna materia preexistente, pero de tal modo que cuando Dios crea nuevas almas no hace una nueva obra porque se llaman obras [divinas] distintas las que difieren en especie, pero los individuos de una especie difieren por accidente. Por lo tanto, cuando se multiplican numéricamente los individuos de una misma especie, no se hace una obra nueva y distinta, sino que la obra ya hecha se dilata y extiende más" (Hexaem. IX, 3, 3, ed. cit. p. 270-271). 
Al comentar el texto bíblico desde la doble vertiente de la tradición exegética cristiana y las nuevas concepciones en juego (la tradición greco-árabe) se hace patente el desacuerdo en puntos fundamentales, tal y como ya se habia planteado la disputa con el grupo "averroista" latino. Para un filósofo creyente no cabe duda (desde su fe) del error de los paganos. Demostrar la falsedad de sus teorias, en cambio, demandó ingentes recursos teóricos y la cuestión nunca quedó resuelta en forma totalmente satisfactoria. Grosseteste asume que el conjunto del saber no puede incluir contradicciones. Luego, si la Biblia (por definición) dice la verdad, debe haber también un modo racional de refutar la posición contraria.

Por lo tanto es válido oponer el texto bíblico a quienes opinan lo contrario, en el convencimiento de que debe haber argumentos racionales para refutarlos. Así sucede, por ejemplo, con la afirmación de la eternidad del mundo o de la materia increada (ver Apéndice I, 8, 1-3) lo cual tiene consecuencias importantes para nuestro tema.

La afirmación de la radical finitud del mundo es el complemento de su radical bondad y ambas se derivan de la creaturidad. Todas las cosas son a la vez buenas y finitas porque son creadas, tienen un mismo principio eficiente (la voluntad divina) y una misma causa final (la glorificación de Dios). Por lo tanto, las diferencias entre las creaturas son de grado, de especie, pero no son diferencias absolutas; como no hay dualismo ontológico, tampoco lo hay cosmológico. De este modo es posible plantear las relaciones del hombre con la naturaleza (el resto de lo creado) en un sentido cristiano distinto de la perspectiva cosmológica aristotélica, pero compatible con ella.

\section{La dignidad del hombre}

El fundamento de esta asunción es, naturalmente, la especial condición del hombre, que ha sido creado "a imagen y semejanza de Dios", lo cual no se dice de las demás creaturas, por nobles que sean (incluidos lo ángeles). La exégesis bíblica apunta por una parte a la correcta interpretación de las palabras, por otra, a proporcionar las claves para entender la realidad del mundo tal como la vemos en la experiencia. Desde ella, apreciamos que el hombre es un ser peculiar, tiene facultades que parecen no existir en otras creaturas incluso genéricamente próximas, como los animales. Ya Aristóteles había señalado la racionalidad como su diferencia específica. Grosseteste quiere extraer además otras consecuencias, pero acentuando más bien su "espiritualidad". ${ }^{16}$

Esta racionalidad espiritual confiere al hombre los siguientes atributos:

16 Para Grosseteste y su círculo el hombre es un animal racional mortal compuesto de un cuerpo material y un alma espiritual, pero es una unidad y no un agregado. Cf. B. Zedler, "Comment on Dom. Pouillon's Paper: Robert Grosseteste and the unity of man", Proceodings of American Cathol. Philosophy Assoc. 27, 1953: 144-155. Según esta autora, hay que considerar un conjunto de obras del círculo de Grosseteste, como el De homine, De homine creato y De anima porque, aunque de autoria dudosa o rechazada, expresan posiciones compartidas por el grupo oxoniense en la primera mitad del siglo XIII. 
a. Ser imagen de Dios uno y Trino;

b. Ser un "microcosmos" o compendio de todo lo creado;

c. Ser necesariamente una sola especie;

d. Ser el señor natural de todas las cosas.

Veremos a continuación estos puntos en detalle. Del primero, que se refiere a la relación entre Dios y el hombre, se derivan los otros tres que representan diversos aspectos de la relación del hombre con el resto de la naturaleza.

a. Imagen de Dios Uno y Trino. Ya indicamos que todas las cosas creadas llevan en sí una impronta o "huella" (vestigium) de su causa primera. El vestigio es un signo natural que remite a una causa (por ejemplo el humo con respecto al fuego), y puede incluso tener alguin tipo parcial de semejanza (por ejemplo la huella tiene la forma del pie), pero no es una semejanza en sentido propio, y por lo tanto de por sí solo no permite conocer la naturaleza propia de la causa. En efecto, analizando el humo sólo es posible deducir alguna propiedad del fuego y así, sólo proporciona un conocimiento referencial e imperfecto. En cambio la imagen, que proporciona una semejanza propia de la causa, sí permite inferir con certeza la esencia de la causa.

Siguiendo la tradición agustiniana, Grosseteste afirma que esta semejanza del hombre con Dios le adviene por el alma espiritual, de modo que sus tres facultades (memoria, inteligencia y voluntad) remiten a las tres personas divinas. ${ }^{17}$ Por cierto que esta relación es analógica y más bien extrínseca, ya que Grosseteste sólo admite hablar de Dios por via negationis. ${ }^{10}$ Pero es real y permite

17 El desarrollo de esta parte es amplio y complejo. Interesa señalar aquí que sus discípulos, a través de la síntesis de Adam Marsh, han insistido en presentar este tema como el central de los diez primeros capitulos de esta parte octava. También han observado la relación biunívoca entre la idea de la imagen y la trinidad: por una parte se encuentra en las tres facultades espirituales la analogia con la Trinidad, por otra, el "hagamos" intenta mostrar (ya que no demostrar) la existencia de las tres personas (oontra paganos, fudios y musuimanes, que la niegan). Adam Marsh considera que los cuatro primeros capitulos justifican la Trinidad a partir del "hagamos" y los resume asi: 1. Se muestra que es muy dificll, casi imposible, explicar esta frase "hagamos"; 2 . Se muestra de qué modo, a partir de la pluralidad de significados de "hagamos" y "nuestra", se declara la pluralidad de personas de Dios único, contra los judios y gentiles; son cuatro razones; 3 . Otras cinco razones para la prueba convincente de que Dios es trino; 4. Se ponen ejemplos de las creaturas para entender la unidad de la Trinidad. Los restantes seis capítulos de este tema proceden de modo inverso, y justifican la imagen trinitaria en la triple distinción de las potencias del alma, también ella de raiz agustiniana; 1 . Se muestra de qué modo el hombre es suma semejanza e incluso ímagen de Dios, según la memoria, la inteligencia y el amor de su parte suprema racional correspondiente a la mente divina memorante, inteligente y amante, y que por tanto todo el hombre ha sido hecho a imagen de Dios en todo aquello que corresponde a la suprema razón, 6. Se divide la imagen de Dios en natural, renovada y deformada, de las cuales la natural nunca se pierde, la renovada se pierde por el pecado, y la deformada se elimina por la gracia del Espíritu Santo; 7. Se muestra que todo lo que se ha dicho anteriormente acerca de la imitación de Dios conviene sola y propiamente al hombre, y que sólo el hombre es imagen de Dios en cuanto sólo a él le es propio ser una imitación próxima; 8. Se muestra en qué sentido el hombre ha sido hecho a imagen de Dios, y la diferencia entre imagen y semejanza; 9. Se muestra por qué el hombre se dice hecho a ímagen de Dios; el Hijo no a imagen sino imagen; y además que los hombres son por imagen, y no imagen ni a imagen; 10 . Se demuestra que al decir "a imagen", etc. el hombre no ha sido hecho sólo a imagen del Hijo o del Padre, sino que ha sido hecho a imagen de la Trinidad. Hist. Doctrin. Litt. Moyen Age 34, 1959: 99-197. 
inferir por una parte la procesión trinitaria, por otra - y esto es lo relevante aquí la capacidad humana de imitar, dentro de sus límites, las obras divinas trinitarias. Por eso el hombre puede acceder a cierta forma de creación, de gobiemo y de providencia sobre los demás seres. Esta semejanza permite al hombre remitir nuevamente a Dios, a través suyo, toda la creación de la cual es compendio, por esa semejanza de natura. Pues aunque Dios, en cuanto divinidad, no tiene ni puede tener una natura común y unívoca con ninguna creatura, incluso la más perfecta posible, en cuanto el Verbo se hizo hombre comunicó en natura univocamente con la creatura racional, y así también en el mundo de la gracia se cumple este proceso de retomo al Padre."

b. Microcosmos. La idea del hombre como microcosmos es de antigua data, ${ }^{20}$ pero el Lincolniense da una versión vinculada a su carácter de imagen de Dios. Ya dijimos que el hombre se asemeja a Dios por el alma, y compendia en su cuerpo las perfecciones de todos los seres materiales. Por eso el cuerpo humano tiene en sí materialmente todos los elementos del mundo y el alma participa de la unidad de la potencia nutritiva y sensible de plantas y animales. ${ }^{21}$

Esta idea del hombre como microcosmos no está desarrollada sino supuesta en esta obra. En un breve opúsculo ${ }^{2}$ se explaya más sobre el sentido de esta afirmación. En cuanto al cuerpo, el hombre resume todo lo material, porque consta de came y huesos, los cuales se componen de los cuatro elementos, teniendo en consecuencia, algo de aire, de agua, de fuego y de tierra. Aunque esta "bioquímica" esté sobrepasada, es claro su sentido, perfectamente actual: los procesos bioquímicos implican a los inorgánicos pero no a la inversa, por su mayor complejidad.

Por otra parte, desde el punto de vista que denominariamos "estructural y funcional", también halla Grosseteste una isomorfia. El cuerpo humano se divide en cuatro partes, que se refieren a los cuatro elementos y sus lugares naturales en el universo. La cabeza se vincula al cielo (que incluye el éter y el fuego, el más noble de los cuatro elementos sublunares), el pecho se relaciona con el espacio del aire, como se aprecia incluso en el proceso respiratorio. El vientre (las funciones digestivas) se relaciona con el mar y el agua, por la naturaleza fluida y acuosa de la digestión, la asimilación y la evacuación. Finalmente los miembros inferiores se relacionan a la tierra, tanto por su posición como por su naturaleza. Esta relación al "hombre cósmico", cuyas reminiscencias esotéricas son notorias, tiene sin embargo en Grosseteste, poco afecto a estos enfoques, un sentido más práctico y

Hexaem. IX, 8, 2 (ed, cit. p. 276).

20 Un estudio del tema en la época contemporánea a Grosseteste en J. Mc Evoy, "Philosophical developments on the Microcosm and the Macrocosm in the thirteenth century", L'home et son univers au Moyen Age, ed. Ch. Wenin, Louvain, 1986, I: 374-381.

${ }^{21}$ Ibid. Añade que la perfecta y completa reversión a Dios se da por una especie de movimiento circular propio de la compleja realidad humana: con el ángel, su alma comporta una unidad de racionalidad e inteligencia; por la unión del alma racional con el cuerpo, que produce el individuo, el hombre participa de las perfecciones de la vida inferior. Es decir, por el alma el hombre comunica con el ángel, que está ontológicamente encima y con los demás vivientes e inanimados, que están ontologicamente debajo.

Quod homo sit minor mundus, ed. L. Baur, Die philosophischen Werke des Robert Grosseteste, Münster, 1912, p. 59. 
preciso. Estas analogias funcionan como fuente de conocimiento (deducción por el principio de semejanza) y por tanto de previsibilidad legal. Son analogias que funcionan regularmente y permiten inferencias científicamente válidas. Al mismo tiempo insinúan una relación óntica profunda entre la estructura humana y la universal.

c. Unidad especifica. La unidad de la especie humana se vincula por una parte con el acto especial divino de creación y por otra con la lógica del sistema piramidal de las perfecciones creadas. La narración bíblica insinúa una consideración especial en cuanto el hombre fue claramente creado como individuo (un varón y una mujer) mientras que de las demás especies vivas se habla en términos de pluralidad. La unidad especifica del hombre está asegurada por el hecho de que todos descendemos de Adán y Eva, de tal modo que los hombres no sólo tengan entre sí una sola semejanza específica sino también un solo vínculo comunitario."

Esta unidad de vinculo comunitario, que Grosseteste no desarrolla en esta obra, pero que preside otros aspectos de su pensamiento, justifica la solidaridad y la responsabilidad del género humano como tal en relación a la naturaleza. Cuando, en los capitulos sucesivos, el Lincolniense habla de "el hombre" (como equivalente a lo que hoy llamariamos "la humanidad" como conjunto) está pensando no en un mero agregado de individuos, sino en este vinculum cognationis que se deriva en última instancia de su único y exclusivo carácter de "imagen de Dios".

d. Dominio sobre la naturaleza. El dominio sobre la naturaleza es una afirmación bíblica y un dato de experiencia. Pero también constatamos que como contrapartida, la naturaleza es hostil al hombre en muchos aspectos, y que su dominio es arduo y difícil. La tradición religiosa judeo cristiana afirma que esa hostilidad de alguna manera se remite al pecado de Adán, que tuvo, entre otras consecuencias derivadas de la expulsión del paraíso, la pérdida de la relación armónica con la naturaleza. La tradición recoge diferentes grados en que esa ruptura ha sido percibida.

En la época de Grosseteste, y más aún en la tradición franciscana, hay una clara tendencia a disminuir la gravedad de la misma, tanto para proclamar la bondad absoluta de Dios que perdona, cuanto para reafirmar la bondad radical de todo lo creado, inclusive el alma humana manchada con el pecado original. La idea de una naturaleza "desviada" (caída pero no conompida) se aprecia en los textos de Grosseteste, que sus discípulos interpretaron muy ceñidamente. El tema del dominio ocupa en forma directa once de los 35 capítulos de la octava parte. De ellos cuatro se refieren al dominio en general o en sentido absoluto, conforme a la bendición de Dios antes del pecado. ${ }^{24}$ Hay que observar una distinción importante.

23

24

Hexaem. VIII, 28, 1, ed. cit. p. 252.

Marsh los resume asi: 13. Se muestra por qué el hombre domina sobre los demás seres animados, tanto antes como después del pecado; 14 . Se muestra el orden y la razón que fundamenta la potestad del hombre sobre todos los seres vivos; 15 . Se muestra el sentido literal de que el hombre está por encima de todas las creaturas; 16 . Se muestra por qué al final de indicar la dominación humana se anade que el hombre domina a todo reptil. 
Mientras que se refiere a la "superioridad" (mayor dignidad) del hombre sobre todo lo creado en general, que incluye los seres inanimados, se habla concretamente del "dominio" sobre los seres vivos. Esta cuestión tiene un interés especial en relación a la "utilidad" de plantas y animales que menciona la Biblia, mientras que no se habla de "utilidad" de las cosas inanimadas.

Los restantes capítulos mencionan la relación con la naturaleza luego de la caída ${ }^{25}$ y entre ellos se intercalan los capitulos que se refieren a la creación de la mujer y a la bendición de propagación (Gen. 1, 27-28). Por lo tanto, según la interpretación de Grosseteste, el pecado, que es posterior a la bendición absoluta inicial, no la suprime aunque atenúa e impide parcialmente sus efectos. Siguiendo ideas agustinianas, admite que la propagación de la especie humana, no impedida por el pecado, se realizó sin embargo de un modo distinto al previsto en el plan divino original, y esto tiene que ver con el "desorden" de la naturaleza carnal, inexistente antes del pecado.

Esta idea del "desorden", de cuño agustiniano y que el Hiponense mismo transfirió a la relación con la naturaleza y a la hostilidad de ésta para el hombre, es retomada por Grosseteste pero en un plano, dirfamos, menos dramático. El "desorden" se manifiesta en la forma de "desobediencia". "Desobedientes son los miembros del cuerpo propio, así como los animales a quienes hay que vencer y domesticar, y como las plantas y los climas. Por eso, siguiendo también ideas de los Santos Padres, Grosseteste sostiene que al principio los hombres y los animales eran vegetarianos, porque las plantas eran naturalmente aptas para su alimento, mientras que luego del pecado, el hombre y otras especies comen came, como un remedio a su debilidad, ${ }^{7}$ idea que le permite añadir consideraciones de tipo moral sobre los beneficios físicos y psíquicos de la abstinencia. Pero en un sentido más profundo, la idea es que este estado de debilidad puede ser reparado, en forma absoluta por la gracia, y en forma relativa y coadyuvante por nuestras propias prácticas, en la medida en que ellas tiendan a asemejarse en lo posible al estado original. De allí que la reconstrucción del estado originario, que Grosseteste desarrolla en las partes finales, y en las cuales se ve un interés por expresarse del modo más científico y seguro posible, tenga - entre otros - el objetivo de proporcionar un cuadro de un estado realmente posible, aunque no sin ayuda divina, para la humanidad futura.

` Adam Marsh los resume asi: 21. Se explica que de modo adecuado, en razón de la desobediencia que dañó a la naturaleza humana, resultó dañada la misma naturaleza; 22. Se muestra por qué los animales no crecen constantemente mientras viven, siendo que los árboles si crecen siempre mientras viven; 23 . Se muestra de qué modo el hombre liena toda la tierra y la somete, según el sentido literal: son cuatro modos; 24 . Se muestra que el hombre y todos los animales de la tierra hubiesen vivido alimentándose en común y en concordia sólo de hierbas, semillas y frutos, si el hombre no hubiese pecado.

Hexaem. VIII, 25, 1, ed. cit. p. 249. 


\section{Algunas ideas para finalizar}

Grosseteste, iniciador de una de las líneas más ricas de la tradición franciscana, la oxoniense, fue un puente entre la tradición sapiencial altomedieval y el aristotelismo ascendente. Algunas de sus ideas, salvando la lógica distancia de siglos y de vivencias culturales, pueden hoy ser motivo de una reflexion filosófica:

$1^{9} \mathrm{El}$ universo es una unidad de relaciones, y el accionar de un sector influye sobre los otros de modo previsible (legal), lo que implica la responsabilidad del agente.

$2^{2}$ Los seres humanos configuran una "familia", es decir, relaciones de congregación y no de agregación. Por eso son solidariamente responsables, como conjunto o especie, en virtud de su capacidad de comprensión y racionalidad. Esto, naturalmente, no obsta a la responsabilidad concreta a individual en cada caso. Lo que se quiere decir es que la relación con la naturaleza es un problema del hombre como especie, de la humanidad como un todo, y no sólo de cada individuo considerado aisladamente.

$3^{2}$ Aunque hay una tendencia al mal y a la negación (producto de la caída original) ni el hombre ni la naturaleza son irredimibles o inmodificables, no sólo desde el punto de vista sobrenatural religioso, sino aun desde una perspectiva natural. Un estado mejor, más ordenado y armónico que el presente es realmente posible y asequible a la racionalidad y la voluntad libre del hombre.

Estas tres ideas, enunciadas en un lenguaje un poco distinto del nuestro, expresan intuiciones básicas de la filosofía natural y la ética actuales. Aun cuando se imponga un mayor y hasta un total deslinde entre lo religioso y lo profano, el núcleo sigue en pie y proporciona un espacio válido y estimulante de diálogo.

\section{APENDICE}

Traducción de algunos textos significativos sobre los puntos anteriormente tratados. ${ }^{z B}$

\section{Parte primera, Capitulo VII (Ed. Dales-Gieben, p. 56-58)}

1. Por lo tanto, el primer sentido de estos textos, comprensibles para todos, es que Dios, al comienzo de los tiempos y de las cosas creadas hizo el cielo, que rodea, circunda y contiene todos los demás cuerpos de este mundo sensible, y esta tierra visible que habitamos; esta tierra era yerma, no germinaban plantas y estaba vacía de animales. Por eso, lo que sigue tenebrae erant super faciem abyssi, et spintus Domini ferebatur super aquas [Gen 1,2] significa que todo el espacio intermedio entre el cielo y la tierra estaba lleno de agua, hechas

\footnotetext{
28 Las fuentes mencionadas son: - Agustín, De civitate Dei, ed. E. Hoffmann, Leipzig, 1896, CSEL 40, 1-2. - Agustín, De Genesi ad litteram, ed. J. Zycha, Leipzig 1894, CSEL 38,1. - Agustín, De libero arbitrio, PL 32. - Agustin, De Trinitate, PL 42. - Basilio, Hexaemeron ed. E. Amand de Mendieta S.R. Rudberg, Berlin 1958. - Beda, Hexaemeron, PL 91. - Boecio, De consolatione philosophiae, PL 63. - Juan Crisóstomo. Homiliae in Genesim, PG 53. - Plinio el Viejo, Historia naturalis, ed. 1. Sillig, Leipzig, 1831, 1856, $5 \mathrm{v}$.
} 
simultáneamente con el cielo y la tierra, aunque quizá no lo mencione porque eran la materia de las cosas intermedias. Por tanto, desde el principio la masa del universo fue perfecta, aunque no estuviesen todas las especies. Sobre el abismo de las aguas intermedias entre el cielo y la tierra habia tinieblas, porque aún no existía la luz que las ilumina; y el espíritu, es decir, la buena voluntad de Dios, iba sobre las aguas por la intención de educir de ellas las especies visibles. Lo que primero hizo el Verbo de estas aguas fue la luz corpórea, que iluminó las tinieblas hasta la tierra; así se dividió el espacio diumo, es decir, las 24 horas equinocciales, de tal modo que durante una mitad se ilumina la tierra y en la otra mitad no, produciéndose el día y la noche, los que sumados hacen un día natural.

2. Después, el Verbo divino, de dichas aguas hizo el firmamento en el que ahora vemos las luminarias del cielo, firmamento cuyo sitio y lugar es muy inferior al cielo hecho al principio. De estas aguas primordiales, una parte quedó sobre el firmamento, que cubrió todo el espacio desde el firmamento superior hasta el primer cielo; y una parte quedó bajo el firmamento, que cubrió todo el espacio desde el firmamento hasta la tierra abajo. Así se completó el segundo día, en el que no se hizo el sol sino la luz que divide el día y la noche por ausencia y presencia. El tercer día fueron congregadas las aguas que están bajo el firmamento, formando los mares y ríos que ahora vemos, a partir de los vapores iniciales. Al producirse esta condensación de los vapores acuosos en aguas más densas, como ocupaban menos lugar y no podía quedar un lugar vacio, fue ocupado este lugar por la parte más sutil de las aguas. Y así, al mismo tiempo que la congregación de las aguas se produjo el aire, porque la evaporación del agua es la generación del aire, y si se produce mucho enrarecimiento y sublimación, se generan también el fuego y la llama. Hecha esta congregación de las aguas en los mares y ríos que vemos, y la ocupación aérea del espacio superior, el Verbo de Dios produjo la tierra que ahora vemos, con los seres terrestres cada uno de los cuales produce una especie semejante a sí por semilla y geminación. El cuarto día fueron hechas las luminarias y las estrellas que actualmente están colocadas en el firmamento, con cuyo movimiento e iluminación dividen el día y la noche y nos señalan las divisiones del tiempo. El quinto día, de las aguas congregadas el Verbo de Dios produjo los reptiles acuáticos y las aves del cielo. El sexto día fueron producidos los animales terrestres y el hombre, creado a imagen y semejanza de su creador. Esta creación del mundo ordenada en seis días es expuesta por Josefo, Beda, Basilio, Ambrosio, Jerónimo y muchos otros, aunque disientan en muchos aspectos que corresponden a la narración literal, como - si Dios quiere vamos a explicar inmediatamente.

\section{Parte primera, Capítulo VIII (Ed. Dales-Gieben, p. 58-62)}

1. La primera palabra: en principio evoca el inicio del tiempo y que el mundo fue hecho al principio del tiempo y que no es indeterminado e infinito en su inicio. Por tanto, con esta única palabra en principio se evita el error de los filósofos que adujeron que el mundo no tuvo inicio temporal, lo que de algún modo dijo e intentó probar Aristóteles en el libro VIII de la Física; también Platón en el Timeo aseguró que anteriormente hubo infinitas inundaciones de diluvios. 
2. Hay algunos modernos, vanidosos filosofantes y más bien insensatos, que dicen que Aristóteles no intentó sostener que el mundo carece de principio temporal, sino que en esto pensó de acuerdo al artículo católico y propuso que el mundo y el tiempo tuvieron un inicio. Contra ellos vale el texto mismo de Aristóteles, y los medios usados para su conclusión, y la última conclusión de su libro, que prueba el primer motor a partir de la perpetuidad del movimiento. Además, todos los intérpretes de este paso de Aristóteles, tanto griegos como árabes, exponen concordantemente este texto sobre la perpetuidad del movimiento, el tiempo y el mundo, es decir, su duración infinita en ambos sentidos. También Boecio, en el libro La consolación de la filosofia [V, prosa 6, PL $63,858-859$ ] asegura que Aristóteles, como Platón, pensó que el mundo carece de ínicio. Después de definir la etemidad, queriendo dejar más claro eso en relación con lo temporal, dice que "el tiempo padece condiciones [condicionamientos], aunque acerca de esto pensó Aristóteles que nunca comenzó ni nunca dejará de ser, puesto que el tiempo tiende a la infinitud; sin embargo de ningún modo debe interpretarse que verdaderamente sea eterno. Pues no se da todo simultáneamente, sino que todo lo futuro aún no ha llegado y no es" [PL 63, 858859]. Por estas palabras es evidente que Aristóteles pensó que el mundo no comenzó ni dejará de ser, sino que es coetáneo a un tiempo infinito. Poco después, dice Boecio en el mismo libro: "No es correcto pensar como Platón, que el mundo no tenga comienzo temporal ni desaparición futura, pensando que el creador es coeterno al mundo creado. Una cosa es tener una vida interminable, que Platón atribuye al mundo; otra cosa es tener la vida interminable totalmente completa presente, lo que manifiestamente es propio de la mente divina". Agustín en el Libro 11 de La ciudad de Dios [XI, 4, CSEL 40, 1, 515] asegura que algunos filósofos pensaron que el mundo es eterno sin inicio, y que no les parece hecho por Dios "grandemente apartados de la verdad y afectados por la enfermedad de la impiedad".

3. Otros, como él mismo dice, "aceptando que el mundo fue hecho, no quieren fijar un inicio temporal de su creación, de modo que se interpreta que fue hecho desde siempre". Se refiere a los antiguos platónicos cuyo ejemplo pone Agustín en el Libro 10 de La ciudad de Dios: "Aunque Platón escribió clarisimamente que el mundo y los dioses fueron hechos por Dios tenjendo principio, pero no fin, sino que por la potentísima voluntad del creador durarán eternamente, de algún modo los platónicos llegaron a interpretar que esto no sea temporal, sino inicio de la sustitución. 'Asi pues' dicen 'si el pie desde la etemidad hubiese estado en el polvo, siempre hubiera existido la huella; sin embargo, nadie dudaria que la huella fue hecha por el calzado; tampoco uno seria anterior a la otra, aunque una hubiese sido hecha por el otro: así -dicen- si el mundo y los dioses siempre existieron, existiendo siempre el que los hizo, son eternos y sin embargo son hechos" [X, 31, CSEL 40, 1, 502-503]. En el Libro XII de La ciudad de Dios [c. 10, CSEL 40,1, 582] refiere Agustín que Apuleyo, como muchos otros, creía que el mundo y el hombre existieron siempre. Poco más abajo, en el mismo libro, relata Agustín el argumento más agudo de los filósofos, con el que intentan probar que el mundo no dejó de ser alguna vez, sino que existió sin principio 
temporal, y sin embargo, fue hecho. En el Libro XIII de La ciudad de Dios dice que Platón consideraba al mundo como un animal felicísimo, máximo y eterno [c.16, CSEL 40, 1, 634]. Ambrosio dice en el libro Hexaemeron [I, 1,3, CSEL 32, 1,4] "parece que Aristóteles afirma que el mundo siempre existió y existirá, mientras que Platón considera que no siempre fue, pero será; muchos otros afirman en sus escritos que ni siempre fue ni siempre será". Aquí Platón parece contradecirse, porque - como es evidente por lo anterior - a veces afirma que el mundo carece de principio, y otras insinúa que tuvo principio. Por eso Agustín, en el Libro XII de La Trinidad [De civ. Dei XII, 13, CSEL 40. 1, 585] dice que Platón confesó claramente que el mundo no siempre existió, esto es, que comenzó a existir, aunque muchos hayan creído que pensó lo contrario que dijo. Basilio, en la Homilia primera del Hexaemeron [I, 2,1; I, 3,8, CSEL 32, 1, 5-6]: algunos filósofos sostienen que este mundo visible de todas las cosas es coeterno a Dios creador y no tiene principio $\mathrm{ni}$ fin. Algunos de ellos de ningún modo conceden que fue hecho por El, sino sólo como cierto oscurecimiento de la potencia del ser divino; opinan que es compuesto, y aunque consideren a Dios como autor, lo es de tal modo que origina una procesión no voluntaria, así como la sombra de un cuerpo o el fulgor de la luz. Plinio, en el Libro II de su Historia natural dice que el numen mundano es eterno, inmenso, ingenerado e inmortal [II, 1,1,1, ed. Sillig, 1,101].

4. Por todas estas cosas y muchas otras que podrían agregarse si no lo impidiera la necesidad de continuar, se hace evidente que muchos filósofos, juntamente con Aristóteles, aseguraron que el mundo carece de inicio temporal; a los cuales golpea y rechaza Moisés con una sola palabra, diciendo en el principio. Afirmamos esto contra algunos modemos, que intentan - contra Aristóteles mismo y sus expositores - hacer de un Aristóteles herético uno católico, creyendo con admirable ceguera y presunción que pueden entender más claramente e interpretar mejor a Aristóteles en lengua latina corrupta que los filósofos gentiles y católicos que conocieron exhaustivamente sus textos en el griego original e incorrupto Y no sólo se decepcionan y frustran queriendo presentar un Aristóteles católico, consumiendo inútilmente su tiempo y las fuerzas de su ingenio, sino que queriendo hacer de Aristóteles un católico, ellos mismos se vuelven herejes. Pero basta de esto.

5. Debe saberse que aquello por lo que fallaron los antiguos al admitir un mundo sin inicio, fue principalmente una falsa imaginación, que los condujo a imaginar un tiempo antes de todo tiempo, así como la fantasía imagina un lugar fuera de todo lugar, y un espacio fuera de todo espacio y así al infinito. Por lo cual tampoco se puede eliminar este error sin que el afecto de la mente se separe del amor a las cosas temporales, para que su mirada, haciéndose inmune a las imágenes pueda trascender el tiempo y entender la eternidad simple, donde no hay ninguna extensión según lo primero y lo posterior, y de la cual procede todo tiempo y lo anterior y lo posterior. Erraban pues en aquel argumento por el que decían: una causa total y plena a la cual ninguna condición es necesario añadir para que se haga existente, necesariamente es coexistente a su efecto total y pleno que existe siempre simultáneamente a su causa. Pues Dios es una causa tal, 
porque es omnipotente, al cual no se añade ninguna nueva condición o potencia, o sabiduría o voluntad, sino que es siempre y uniformemente del mismo modo. Por lo cual, si el mundo fue hecho por él, siempre coexistió con él y así el mundo, como tampoco él, no tiene principio. Y si el mundo no es hecho, tampoco tiene principio. Estos añaden el ejemplo mencionado del contacto del pie en el polvo y la huella, del cuerpo y la sombra, de la luz y el fulgor.

6. Pero no entiende que la expresión "coexistencia simultánea del efecto total con la causa total" implica que la causa y el efecto caigan en el mismo género de medida, es decir, que ambos sean temporales, o eternos. En aquellas cosas que pertenecen al mismo género de medida, el argumento anterior es necesario pero si la causa y lo causado no participan del mismo género de medida de ser, no es válida la regla que dice: existiendo la causa, necesariamente coexiste con lo causado. Y como Dios es eterno, mientras que el mundo y el tiempo son temporales, el tiempo y la eternidad no son el mismo género de medida, y no se aplica la regla de la coexistencia de causa y causado. (...)

\section{Parte octava, Capitulo I (Ed. Dales-Gieben, p. 217-218)}

1. Hagamos al hombre a nuestra imagen y semejanza [Gen 1,26]. Muy breve es este texto, pero fecundísimo de amplios y profundos sentidos, de modo que si esta fecundidad debiera ser explicada y descrita en detalle, pienso que no cabrian en el mundo los libros que debieran escribirse. Comprehende lo más secreto de Dios y lo más sagrado del hombre. Muestra la Trinidad del Dios único y la suprema dignidad de la condición humana, pues dice que el hombre ha sido hecho a imagen de la suprema Trinidad. La imagen, como dice San Agustín en La Trinidad [XI, 5, 8, PL 42, 991], es máxima semejanza. Pero la semejanza es de dos clases: una de igualdad y paridad, otra de disparidad e imitación. Por tanto también la imagen es doble, o bien de máxima semejanza según paridad, o de máxima semejanza según imitación. De acuerdo a la primera acepción de imagen, sólo el Hijo es imagen de Dios Padre. Pues todo lo que tiene el Padre, lo tiene igualmente el Hijo. Y todo lo que hace el Padre, de la misma manera es obrado por el Hijo. $Y$ asi como el Padre tiene vida en si mismo, asi dio al Hijo tener vida en si mismo [Jn 5 , 26]; digo vida, esto es, sustancia plena y total de divinidad, no multiplicada, $\mathrm{ni}$ dividida, ni disminuida. Y de este modo es semejanza del Padre según igualdad. En cambio el hombre es semejanza de la Trinidad de Dios por imitación. Pues la creatura no puede compararse con su hacedor, ni univocarse en algo con él, pero puede imitarlo de algún modo.

2. Puesto que el hombre, según la Escritura, es imagen de la Trinidad de Dios, y por tanto es suma semejanza imitativa de la Divina Trinidad (no sería suma semejanza imitativa si no pudiese ser imitado según todo aquello de lo cual es suma semejanza, de modo que tenga en la imitación, como impresión vestigial, todo lo que en sí tiene en posesión sustancial) la explicación de estas palabras exigiria tomar en cuenta todo lo que en sí tiene la Trinidad Divina, y de aquellas determinadas que están en Dios se llegaria a las determinaciones imitadas en el hombre. Dios es todo en todos, vida de los vivientes, forma de los conformados 
[forma formosorum], belleza de los bellos [species speciosorum]; y en todas estas cosas el hombre es máxima semejanza imitatoria. Por lo cual también el hombre, en cuanto es imagen de Dios, es de algún modo todas las cosas. Y por eso la explicación de estas palabras requiere más que una explicación de los conformados y los bellos y todas las cosas, porque, hay una coaptación recíproca entre Dios, el hombre y aquellas cosas. Luego no podemos esperar esta explicación por parte del hombre. Y menos de mi, hombre imperito. Porque cualquier cosa que el hombre llegue a explicar de esto, no es más que lo que es un punto en relación a la linea, un grano en relación al desierto de arena, o una gota de lluvia al agua del mar, o un átomo en relación a todo el mundo. Pero en cuanto Dios se digne asistirme, podré balbucear algunas breves palabras.

\section{Parte octava, capítulo III (Ed. Dales-Gieben p. 220-221)}

1. De que Dios sea tres personas se sigue que Dios es luz, no corpórea sino incorporea; o mejor, ni corpórea ni incorpórea, sino superior a ambas. Pues toda luz de por sí natural y esencialmente genera su esplendor. La luz generante y el esplendor generado necesariamente se complementan y de si espiran mutuo fervor. Ahora bien, generante y generado o son uno y otro, o no uno sino otro, o no otro sino uno, o ni uno ni otro, sino otro distinto, o ni uno ni otro ni otro distinto. De los cinco miembros de esta división, es imposible que cuatro correspondan a Dios y alguno de estos en Dios o en otro. Pues de ningün modo es posible que el generado no sea uno, ni otro ni distinto del generante. Tampoco es posible que el generado sea otro ni uno en relación al generante. Y en Dios no es posible que generante y generado sean diversos, puesto que otro díverso se dice por diferencia accidental. Tampoco es posible que en Dios el generante sea otro que el generado porque en Dios no hay multitud de sustancias. Queda pues que el generado no sea otro distinto sino solamente otro que el generante; y lo mismo para el espirante y el espirado. Hay por tanto en Dios uno y otro y un tercero, cada uno de los cuales es una sustancia indivisa de naturaleza racional, y así son tres personas, y no puede haber ni pensarse en un cuarto. Pues ¿qué cuarto podría añadirse a la luz generante, al esplendor generado y al que procede de ambos por fervor mutuo?

2. Además, de esta trinidad de personas se sigue que Dios es memoria eterna y siempre memorante. Pues él es retención (memoria) sin ningún olvido de todas las ciencias [conocimientos] sin haberlas recibido de otra parte. Pero la memoria en acto memorante no puede sino generar de sí una inteligencia totalmente similar a sí. Pues el acto mismo de recuerdo es inteligencia de sí y generación de algo similar. Pero el generante y la inteligencia generada no pueden sino producir de sí mutuo amor. Por tanto hay en Dios algo uno como memoria generante, algo otro como inteligencia generada y un tercero como amor procedente de ambos; y a esto no puede añadirse un cuarto.

3. Quizá de esta manera pueda probarse Dios Padre, e Hijo y en consecuencia Espíritu Santo, en cuanto él mismo hace nacer a otros, como escribe Isaías: Acaso yo, que hago parir a otros, yo mismo no pariré, dijo el Señor? Yo, que doy a otros 
la vida, seré estéril? dijo el Señor tu Dios [46, 9]. Pues lo que se atribuye a la causa eficiente, lo tiene en si como se le atribuye, o en si de modo excelente. Por tanto, como parir y generar es transmitir la propia sustancia a otro, o bien se trasmite al otro toda su sustancia porque no puede trasmitirse en parte ya que esto implicaria disminución de la potencia, o hace algo proporcional a esto más excelente. Trasmitir a otro toda la propia sustancia reteniéndola toda para sí es lo más admirable y no hay nada mayor que pueda decir verdaderamente generar o parir.

4. Hacer esto parece ser la mayor potencia. Pues la máxima potencia que atribuyeron a Dios algunos y los más grandes filósofos gentiles fue que Dios, a partir de una materia íngénita que él mismo no creó, formó el mundo a la manera de un artesano y artífice. Pero es incomparablemente mayor crear la materia y formar el mundo de la nada, y así del puro no ente hacer el máximo ente después de si mismo; por esto incomparablemente más es generar algo, no de otro ni de la nada, sino de la propia sustancia, que sea en todo tanto cuanto ella misma es. Luego esto hizo la suma potencia; de otro modo no seria la potencia máxima, porque podria pensarse otra mayor.

[...]

\section{Parte octava, Capítulo IV (Ed. Dales-Gieben p. 222-223)}

1. Con respecto a esto estamos conformes con estas razones que prueban la trinidad en unidad. Pero para illustrar de algún modo lo que se ha probado, añadiremos unos ejemplos. Pues la comprensión de la Trinidad nos es máximamente necesaria. Ya que el amor a ella es salud del alma y sin este amor ninguna salud hay en el alma. Pero tanto se ama, cuanto se comprende con fe o inteligencia. Pues es la misma belleza la que lleva al amor del creyente y la comprensión del que entiende.

2. Los ejemplos de la Suma Trinidad que suelen dar son los siguientes, y no son sólo ejemplos, sino que evidentemente han sido aportados a la Suma Trinidad como argumentos con eficacia probatoria de la Trinidad misma. Pero ahora, para evitar el detalle no los expondremos como argumentos sino sólo como ejemplos que ayudan a la imaginación.

3. Un ejemplo es que en toda cosa compuesta existe materia, forma y la composición de ambas. La primera de ellas conduce a la aprehensión de la potencia del Padre, porque la creó de la nada con potencia infinita, puesto que las cosas creadas mismas exceden infinitamente a la nada. La segunda lleva a la comprensión de la sabiduria del Hijo, porque en toda forma, corpórea o incorpórea, está descrita y resplandece la sabiduria infinita. La tercera conduce a la aprehensión del Espiritu Santo, que es amor y conjunción del Padre y del Hijo.

4. Otro ejemplo es que en toda cosa hay magnitud, figura y orden. La magnitud conduce a la aprehensión de la potencia en el Padre; la figura al Hijo, porque es esplendor del Padre y figura de su sustancia; el orden conduce a la benignidad del Espiritu Santo, que ordena a cada una de las cosas a la belleza y utilidad de cualquier otro. 
5. El tercer ejemplo es que en toda cosa hay número, peso y medida. La medida conduce a la aprehensión de la potencia que contiene todo; el número a la sabiduría, porque según Agustín sabiduría y número son lo mismo [De lib. arb. II, 11,32 , PL 32, 1258]; y el peso, que es inclinación de la cosa a la colocación propia y por tanto al orden propio, aquietando a la cosa en su colocación propia y orden propio, insinúa así la benignidad del Espíritu conservador del orden.

6. Luego la materia, la magnitud y la medida muestran la potencia creadora, formativa y continente. La forma la figura y el número muestran la sabiduria creante, formante y continente. La composición, el orden y el peso muestran la bondad creante, formante y continente.

7. He aquí pues los tres ejemplos de la Trinidad que se dan universalmente en todas las cosas. Y entre las cosas corpóreas, el ejemplo más manifiesto de la Trinidad es el fuego o luz, que por necesidad genera de sí esplendor, y estos dos se reflejan en mutuo fervor. En la conjunción de lo corpóreo con lo incorpóreo, los primeros ejemplos están en las formas sensibles, y las figuras de las formas sensibles generadas en los sentidos, y la intención del alma que conjuga la especie generada en el sentido con la forma generante exterior al sentido. Y en éstos lo más evidente es el ejemplo de la visión. Pues el color de la cosa coloreada genera de sí una especie similar a sí en el ojo del que ve, y la intención del alma del que ve conjuga la especie de color generada en el ojo con el color generante exterior; y así une el generante y el generado de tal modo que la aprehensión visual no distingue entre la especie generada y el color generante. Y del mismo modo se da esta Trinidad en cualquiera de los sentidos externos.

[...]

\section{Parte octava, capítulo XIII (Ed. Dales-Gieben, p. 236-239)}

1. Sigue Y domine sobre los peces del mar, y las aves del cielo y las bestias de la tierra, sobre toda creatura y sobre todo reptil que se mueva sobre la tierra len 1 , 26]. La causa de este dominio sobre los animales la señala Jerónimo: "Dios dio el dominio al hombre antes del pecado, no necesitándolo. Pues el hombre necesitó un apoyo en el dominio de los animales después de caído" [Beda, Hexaem. I, PL $91,31 \mathrm{Cl}$. Estas palabras de Jerónimo no deben entenderse en el sentido de que el hombre hubiese carecido de dominio sobre los animales si no hubiese pecado, sino que aquel dominio primordial recibido antes del pecado, tal como ahora es, resultó ayuda después del pecado. Pues en virtud de aquel primer dominio tiene ahora el hombre la posibilidad de domar los demás animales y usarlos para el subsidio de esta vida en pena, uso del cual no hubiera necesitado el hombre si no hubiese pecado.

2. Dios preordenó esta ayuda futura de los animales para el hombre caído. Pues su sabiduría dispuso un orden tal de las cosas que, sea que el hombre cayera o que perseverara sin pecado, todas le estarian sujetas y le servirian adecuadamente. Sin embargo, si el hombre no hubiese pecado, le servirian al hombre con suave y obediente disposición. Pero después que el hombre pecó, la creatura se separó en tormento contra los injustos, pero aun en ese estado no dejaron de servirle. Pues como se ha dicho antes, aquellas cosas que se consideran nocivas, 
dañan "o bien penalmente" de modo justo, "o esfuerzan saludablemente, o ponen útilmente a prueba, o enseñan a los ignorantes" [Agustín, De Gen. ad litt. III, 17, CSEL 28, 1, 82] y así siempre suministran algún uso útil al hombre. Pues cuando dañan penalmente a los que es justo danar - porque nada es dañado injustamente aunque muchos dañen injustamente - es totalmente un bien justo y con su daño penal prestan un ministerio útil al género humano. Pues cuando el malo es castigado justamente, es mejor para él, porque es justo, que salvarse de la pena. Por lo cual, también para aquél que es dañado la pena misma es útil, porque por su causa se hace más justo y mejor.

3. Por tanto, antes del pecado el hombre tuvo dominio potestativo sobre las demás creaturas de este mundo sensible. Según aquella parte [aspecto] en que fue hecho a imagen de Dios precedía a todos los demás. Pues era justo que según su razón perfectamente obediente al Creador y en virtud de esa obediencia no siendo nunca turbado por algún movimiento perturbado e irracional, mantenía a los carentes de razón bajo su dominio potestativo e imperturbado. Por eso el obispo Juan de Constantinopla dice que antes del pecado todas las bestias estaban sujetas al hombre; el que ahora lo dañen es una pena del primer pecado [In Gen. hom. IX, 4-5, PG 53, 78-80]. Lo que podemos considerar y comprender indubitablemente a partir de que ahora apreciamos en el hombre lapso la mortalidad de su vida por el pecado. Pues si caído tanto vale para que impere cotidianamente sobre tantas bestias como sabemos, pues aunque por la fragilidad de su cuerpo puede ser muerto por muchas fieras, sin embargo no puede ser dominado por ninguna, sino que él mismo domina a tantas y propiamente a todas, ¿qué puede pensarse de su reinado? ¿Acaso la potestad de dominar no habría sido tanto más eficaz cuanto más libre de condenación y más elevado fuera su estado? Pues en el paraíso todos los animales eran felices bajo el dominio del hombre, concordantes entre sí y obedientes al hombre.

4. Cuando el hombre, a causa del pecado, hubo retrocedido y declinado en su obediencia a su superior, fue justo que sintiera adverso el orden natural que le estaba sujeto, por su desobediencia contumaz. Por dicha justicia también la came se hizo rebelde al espíritu y los que carecen de razón se hicieron repugnantes al hombre. Sin embargo el hombre no perdió su potestad natural de dominio, es decir la potestad imperativa de la razón. Pero como esta potestad está debilitada y viciada por el pecado y resulta menos capaz de obediencia a la razón imperante ejercer el oficio de dominación suave e imperturbadamente en sus subordinados. Pero tampoco carece totalmente de acto de dominio. Pero éste no es, como se ha dicho, integralmente completo y perfecto, sino que la potestad de dominio está debilitada y es menos capaz de producir obediencia en la sujeción de los imperados.

5. Sucede así como si ves hoy el jefe de una familia, sano de mente y cuerpo y próspero en todas las cosas, toda la familia prontamente obediente a todos sus mandatos, sin existir en ella ninguna rebelión entre sí o en relación al señor sino que todos están concordes en paz, cumpliendo ordenadamente el imperio del señor y en todo está ese imperio ejerciéndose sin ninguna rebelión, sin murmuración y con delectación y máxima facilidad. Verás mañana a ese mismo jefe de 
familia, a causa de su propio vicio, con el cuerpo debilitado y muy apartado de la rectitud de la razón, también en muchas cosas toda la familia estará igualmente debilitada y menos capaz de realizar las acciones que antes realizaba fácil y gustosamente; toda la tranquilidad de paz y orden que hoy existe en la casa del padre de familia, mañana resultará un tumulto confuso y perturbado. Sin embargo existe en ese jefe de familia una potestad de dominio, aunque corrupta y errónea; y existe en la familia un deber natural de obediencia, aunque con dificultades para obedecer y con exigencia de justicia para que el señor no abuse de su dominio; además la desobediencia al señor no libera de la servidumbre. Así también ha sucedido con el género humano en relación al primer hombre.

6. Pues asi como si el hombre no hubiese pecado, todas sus aprehensiones y apetitos animales observarian el imperio de la razón perfecta y obedientemente, sin ninguna rebelión a la razón y sin tumulto ni repugnancia entre sí, habiendo pecado el hombre no obedecen al imperio de la razón sino por cierta fuerza y coacción, estando también entre sí con tumulto y repugnancia: y así también los animales que son exteriores al hombre, si el hombre no hubiese pecado, le hubiesen sido perfectamente obediente y totalmente pacíficos entre si; pero ahora, habiendo pecado el hombre, no conservan paz entre si sino repugnancia tumultuosa. Pues a ejemplo de lo que sucede en el hombre, que es un mundo en pequeño, sucede en el orden o perturbación del orden del mundo mayor por la acción del hombre.

7. En virtud de aquella primigenia potestad del hombre, todo lo que ahora no puede dominar por fuerza, lo domina y lo sujeta por medio de la razón; y aunque el hombre haga esto con trabajo, porque lo domado y sujeto se rebela, ni es obediente a la sujeción ni tuvo antes uso de los que había vencido, venciendo ahora. Así pues envuelve a las bestias marinas y otras bestias enormes en redes, las atrapa con anzuelo o las supera con algún otro ardid de la razón. El hombre encierra al león - cuya fuerza y rugido ningún animal puede soportar - en estrechos cubículos gracias a artificios ingeniosos [trampas] de su razón. Del mismo modo vuela más que las aves, si no con el cuerpo, sí con su ingeniosa razón. A todas las conduce hacia abajo, las captura y las doma con artificios racionales. Por eso también Santiago dijo: Todas las bestias de la naturaleza y las aves y las serpientes y los demás [animales] son domados y han sido domados por la naturaleza humana $[3,7]$.

8. Luego se ha dicho con razón $Y$ preside a los peces del mar, etc. Pues antes del pecado, cuando las cosas obedecían perfectamente a su Señor y no había abuso en su dominio, hubo en todos una potestad de dominio natural perfecta e íntegra y un dominio perfecto en acto, imperio razonable y justo del señor en todos perfectamente obedientes. Después del pecado, en cambio, conserva la potestad natural de dominio, aunque disminuida, viciada y corrupta, y el acto de dominio está ímpedido, y tampoco los subordinados se prestan al deseo del señor con obediente ministerio, sino que deben ser coaccionados por la fuerza con un ardid para imponerles el yugo. 
1. Y adviértase que los animales están sometidos a la potestad humana en el mismo orden según el cual fue narrada su creación. Pues primero se dijo: produzcan las aguas reptiles vivientes [Gen 1,20], por lo cual se entiende el género de los peces, se anade y las aves sobre la tierra [1,21]; y finalmente se refiere a los animales terrestres producidos de la tierra $[1,24]$. Pues primero se confiere dominio a los animales más alejados de nosotros, después a los intermedios y por último a los próximos. Los más alejados son los acuáticos, más próximos son las aves y los más próximos son los animales terrestres. Se indican primero los animales menos susceptibles de domesticación, segundo aquellos que admiten mayor disciplina y en tercer lugar los que admiten una domesticación máxima. Es necesario tomar aquí la palabra "bestias" referida en general a todos los animales terrestres que no son reptiles. Pues aquí el nombre de animales de la tierra comprende a los reptiles terrestres y a las bestias. Y en este orden se insinúa la majestad del dominio humano: primero son dominados los más alejados y menos aptos a la obediencia, lo que es indicio manifiesto del dominio excelente y poderoso.

\section{Parte octava, capítulo XXIII (Ed. Dales-Gieben, p. 246-247)}

1. Lo que sigue: Y llenad la tierra y sometedla [Gen 1,28] es propio solamente del hombre y no es común a los demás géneros de animales. Pero ¿de qué modo llena la tierra el hombre, cuando una sola cuarta parte está habitada y ella misma no toda? A esto responde Basilio [Hexaem. X, 14, ed. cit. p. 200-204] que el hombre llena la tierra no por habitación [real] sino por potestad. Pues Dios dio al hombre el dominio de toda la tierra, lo cual hace por medio de la razón, cuando investiga y conoce la medida y disposición del orbe, cuando percibe que el clima nórdico es inhabitable por el frio y que la zona tórrida impide la instalación por exceso de calor, [cuando] elige lo que es útil para la habitación y abandona lo que no es conveniente para ella. Por ej. si alguien compra trigo, toda la cantidad de trigo comprado es del comprador; pero éste desecha las piedras y otras cosas inútiles mezcladas con el trigo, y elige el grano útil para comer. Así también el hombre domina toda la tierra, y elige alguna parte de ella útil para habitar, otra apta para sembrar, otra para el pastoreo de los animales y otra para otros usos, y abandona el poder sobre otras [partes] que no son adecuadas a las necesidades de su vida. Pero no está menos bajo su potestad la parte desechada que la elegida, puesto que puede, si quiere, entrar en la que abandonó como habitáculo inútil, para habitarla. Pues está en el poder del hombre elegir una zona tómida o fría para habitar y usarla como habitación, aunque por su inclemencia no pueda continuar allí habitándola. Del mismo modo, teniendo para sí comidas diversas, algunas saludables y otras nocivas, ambas están en su poder, sea para comer o para desechar. Pero no se come impunemente comida nociva. Sino que si sabe, elige esto para comer y eso para tirar, y así ejerce su potestad sobre ambas de modo conveniente. $Y$ tal vez antes del pecado el hombre pudo habitar, si quería, cualquier parte de la tierra 
sin daño para su cuerpo. Pues está toda en la potestad natural del hombre y también puede ser bien usada en aquellas partes que espontáneamente no se usan; pues no usándola para los usos necesarios a la vida, de algún modo se la emplea bien, al evitar los daños en que se podría incurir por habitar en esa inclemencia.

2. También el hombre obtiene un fruto utilísimo de todas las partes de la tierra, habitables o inhabitables, es decir, como objeto de alabanza al Creador aspientísimo, que temperó con la parte media los extremos contrarios inclementes y la tornó habitable. Por lo tanto también las partes de la tierra que el hombre no habita por su inclemencia, le sirven generando la templanza de la parte que habita.

3. Además, si hubiese partes de la tierra inhabitables a causa de la dureza de la tierra escarpada, la parte de la tierra inhabitable persiste en su estado. Por lo tanto las partes que no se habitan, pero son sostén de la parte habitable, sirven también al hombre que es habitante absoluto de la tierra.

4. Llena pues toda la tierra y la sujeta toda a sí, mientras la usa toda bien y la domina toda con potestad racional. Esto sólo sucedió en el estado paradisíaco perfecto, cuando vivía allí libre de pecado. 